\title{
Analysis of forced convective heat transfer of nanofluids over a moving plate by the homotopy perturbation method
}

\author{
N. Dalir*, S.S. Nourazar** \\ *Department of Mechanical Engineering, Amirkabir University of Technology, Tehran, Iran, E-mail: dalir@aut.ac.ir \\ **Department of Mechanical Engineering, Amirkabir University of Technology, Tehran, Iran, E-mail: icp@aut.ac.ir \\ cross $^{\text {ref }}$ http://dx.doi.org/10.5755/j01.mech.22.6.12890
}

\section{Introduction}

Nanofluids, which are considered as suspensions of nanoparticles in base fluids, show substantial enhancement in thermal properties compared to regular fluids. Nanofluids enormously enhance the thermal conductivity of base fluid, and thus, they can be used in many industrial applications such as nuclear reactors, transportation and electronics. Due to the tiny size of nanoparticles, nanofluids are very stable. The suspended nanoparticles in nanofluids are responsible for changing the thermal properties of the base fluid. Nanofluids are considered to offer important advantages over conventional heat transfer fluids.

During the last decade, many researchers focused on measuring and modeling the thermal conductivity of nanofluids. Choi et al. [1] indicated that adding a low amount of nanoparticles to conventional heat transfer liquids increased the thermal conductivity of the fluid up to two times. Maiga et al. [2] studied the nanofluid effect on forced convection heat transfer enhancement. The problem of viscous boundary layer flow over a moving flat plate appears in many industrial processes, such as manufacture and extraction of polymer and rubber sheets, paper production, wire drawing, and continuous casting. Weidman et al. [3] solved the problem of self-similar boundary layer flow over a moving plate to show the effects of wall transpiration and plate movement. Xu and Liao [4] studied the boundary layer flow over a flat plate with a constant velocity opposite in direction to that of the uniform free stream by using the homotopy analysis method (HAM). Bachok et al. [5] investigated the steady boundary layer flow of a nanofluid over a moving flat plate in a uniform free stream. Khan and Aziz [6] investigated numerically the natural convective flow of a nanofluid over a vertical plate with a constant surface heat flux. Bachok et al. [7] studied numerically the boundary layer flow of nanofluids over a fixed or moving flat plate with a uniform free stream. They used the shooting method to solve the problem and concluded that the inclusion of nanoparticles into the base water fluid had produced an increase in the heat transfer coefficients. Wang and Mujumdar [8-10] reviewed the theoretical, numerical, and experimental investigations and heat transfer characteristics on nanofluids. Dalir and Nourazar [11] investigated the twodimensional steady forced convection boundary layer flow of various nanofluids over a moving impermeable flat plate where the plate moved with a constant velocity.

In the present paper, the steady laminar boundary layer heat transfer of various nanofluids over an impermeable moving flat plate is investigated. The governing differential equations are transformed by the similarity transformations to two nonlinear ordinary differential equations, and then the resulting nonlinear ODEs are solved using the semi-analytical homotopy perturbation method (HPM) for six types of nanoparticles: copper $(\mathrm{Cu})$, alumina $\left(\mathrm{Al}_{2} \mathrm{O}_{3}\right)$, titania $\left(\mathrm{TiO}_{2}\right)$, copper oxide $(\mathrm{CuO})$, silver $(\mathrm{Ag})$ and silicon $\left(\mathrm{SiO}_{2}\right)$ in the water based fluid with $\operatorname{Pr}=6.2$. The effects of the nanoparticles volume fraction and the nanoparticles type on the heat transfer characteristics, and mainly on the local Nusselt number, are investigated. Although a part of the problem of present study has previously been solved numerically using a shooting algorithm in [11], but in the present study three new types of nanoparticles, i.e., $\mathrm{CuO}, \mathrm{Ag}$ and $\mathrm{TiO}_{2}$ in the water based fluid are examined and discussed as nanofluids. The temperature profiles are also demonstrated for various values of the nanoparticles volume fraction and for various nanoparticles type.

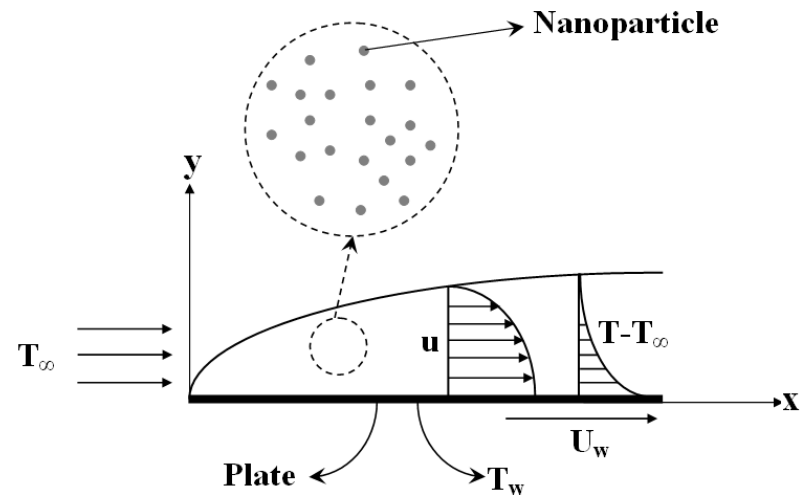

Fig. 1 Schematics of the problem and physical coordinates

\section{Mathematical formulation}

The steady 2-D laminar boundary layer flow over a continuously moving flat plate in a water-based incompressible nanofluid which can contain various types of nanoparticles, namely $\mathrm{Cu}, \mathrm{Al}_{2} \mathrm{O}_{3}, \mathrm{TiO}_{2}, \mathrm{CuO}, \mathrm{Ag}$, and $\mathrm{SiO}_{2}$, is considered. The schematics of the problem and physical coordinates are shown in Fig. 1, where it is assumed that the plate is impermeable and has a constant velocity $U_{w}$ and a constant temperature $T_{w}$. Also, in Fig. $1, u$ is the nanofluid velocity inside hydrodynamic boundary layer, $T$ is the nanofluid temperature inside thermal boundary layer, and $T_{\infty}$ is the nanofluid temperature far away from the moving plate. The nanoparticles are assumed to have a uniform spherical shape and size. With these assumptions, the laminar boundary layer equations of mass, momentum and energy conservations are as follows:

$$
\frac{\partial u}{\partial x}+\frac{\partial v}{\partial y}=0
$$




$$
\begin{aligned}
& u \frac{\partial u}{\partial x}+v \frac{\partial u}{\partial y}=\frac{\mu_{n f}}{\rho_{n f}} \frac{\partial^{2} u}{\partial y^{2}} ; \\
& u \frac{\partial T}{\partial x}+v \frac{\partial T}{\partial y}=\frac{k_{n f}}{\left(\rho C_{p}\right)_{n f}} \frac{\partial^{2} T}{\partial y^{2}},
\end{aligned}
$$

where $u$ and $v$ are velocity components in the $x$ - and $y$-directions, respectively. The boundary conditions of the velocity and temperature for the system of Eq. (1)-(3) are as follows:

$$
\left.\begin{array}{l}
u=U_{w}, v=0, T=T_{w} \text { at } y=0 \\
u \rightarrow 0, T \rightarrow T_{\infty} \text { as } y \rightarrow \infty,
\end{array}\right\}
$$

where $T_{\infty}$ is the free stream temperature which is a constant. It is worth mentioning that $\mu_{n f}$ is the viscosity of the nanofluid, $\rho_{n f}$ is the density of the nanofluid, $\left(\rho C_{p}\right)_{n f}$ is the heat capacity of the nanofluid, and $k_{n f}$ is the thermal conductivity of the nanofluid, which are given as $[8,9]$ :

$$
\begin{aligned}
& \rho_{n f}=(1-\varphi) \rho_{f}+\varphi \rho_{s} ; \\
& \mu_{n f}=\frac{\mu_{f}}{(1-\varphi)^{2.5}} ; \\
& \left(\rho C_{p}\right)_{n f}=(1-\varphi)\left(\rho C_{p}\right)_{f}+\varphi\left(\rho C_{p}\right)_{s} ; \\
& \frac{k_{n f}}{k_{f}}=\frac{\left(k_{s}+2 k_{f}\right)-2 \varphi\left(k_{f}-k_{s}\right)}{\left(k_{s}+2 k_{f}\right)+\varphi\left(k_{f}-k_{s}\right)},
\end{aligned}
$$

where $\varphi$ is the nanoparticles volume fraction, $\rho_{f}$ and $\rho_{s}$ are densities of the fluid and the nanoparticles, respectively.

In order to transform the governing Eqs. (1)-(3) and the boundary conditions of Eq. (4) to ordinary differential equations (ODEs), the following similarity transformations are used:

$\eta=y\left(\frac{U_{w}}{v_{f} x}\right)^{0.5} ; f(\eta)=\frac{\psi(x, y)}{\left(U_{w} v_{f} x\right)^{0.5}} ; \theta(\eta)=\frac{T-T_{\infty}}{T_{w}-T_{\infty}}$,

where $\eta$ is the dimensionless similarity variable, $f$ is the dimensionless stream-function, and $\theta$ is the dimensionless temperature. $v_{f}$ is the kinematic viscosity of the base fluid and $\psi(x, y)$ is the stream-function which satisfies continuity Eq. (1)

Using the similarity transformations of Eq. (6), Eqs. (2)-(3) reduce to two nonlinear ODEs as follows:

$$
\begin{aligned}
& f^{\prime \prime \prime}+\frac{1}{2}(1-\varphi)^{2.5}\left(1-\varphi+\varphi \frac{\rho_{s}}{\rho_{f}}\right) f f^{\prime \prime}=0 ; \\
& \theta^{\prime \prime}+\frac{\operatorname{Pr}}{2}\left(1-\varphi+\varphi \frac{\left(\rho C_{p}\right)_{s}}{\left(\rho C_{p}\right)_{f}}\right) f \theta^{\prime}=0
\end{aligned}
$$

and applying transformations of Eq. (6) on Eq. (4), the transformed boundary conditions become:

$$
f(0)=0 ; f^{\prime}(0)=1 ; f^{\prime}(\infty)=0 ; \theta(0)=1 ; \theta(\infty)=0 \text {, }
$$

where prime denotes differentiation with respect to $\eta$. The quantities of engineering interest are the local skin friction coefficient $C_{f, x}$ and the local Nusselt number $N u_{x}$ which are defined as [10]:

$$
\left.\begin{array}{l}
C_{f, x} R e_{x}^{0.5}=\frac{f^{\prime \prime}(0)}{(1-\varphi)^{2.5}} \\
N u_{x} R e_{x}^{-0.5}=-\frac{k_{n f}}{k_{f}} \theta^{\prime}(0),
\end{array}\right\}
$$

where $R e_{x}=U_{w} x / v_{f}$ is the local Reynolds number.

\section{Solution by homotopy perturbation method (HPM)}

Using the homotopy perturbation method (HPM) [12-13], the original nonlinear ODEs are divided into some linear ODEs which are easily solved in a recursive manner by symbolic software such as MATHEMATICA.

According to the HPM, we construct a homotopy of Eqs. (7)-(8) as follows:

$$
\begin{aligned}
& H(f, p)=f^{\prime \prime \prime}-\alpha^{2} f^{\prime}+ \\
& +p\left(\frac{1}{2}(1-\varphi)^{2.5}\left(1-\varphi+\varphi \frac{\rho_{s}}{\rho_{f}}\right) f f^{\prime \prime}+\alpha^{2} f^{\prime}\right)=0 ; \\
& H(\theta, p)=\theta^{\prime \prime}-\beta^{2} \theta+ \\
& +p\left(\frac{\operatorname{Pr}}{2}\left(1-\varphi+\varphi \frac{\left(\rho C_{p}\right)_{s}}{\left(\rho C_{p}\right)_{f}}\right) f \theta^{\prime}+\beta^{2} \theta\right)=0 .
\end{aligned}
$$

Due to the HPM, the following series in terms of powers of $p$ are substituted in Eqs. (11)-(12):

$$
\left.\begin{array}{l}
f=f_{0}+p f_{1}+p^{2} f_{2}+\cdots \\
\theta=\theta_{0}+p \theta_{1}+p^{2} \theta_{2}+\cdots
\end{array}\right\}
$$

Afterwards some algebraic manipulations, equating the identical powers of $p$ (i.e. $p^{0}, p^{1}$, and $p^{2}$ ) to zero gives following equations with the corresponding boundary conditions (noting that the boundary conditions are also obtained by substitution of the series of Eq. (13) in boundary conditions of Eq. (9)):

$$
\begin{aligned}
& \left.\begin{array}{ll}
p^{0}: & f_{0}^{\prime \prime \prime}-\alpha^{2} f_{0}^{\prime}=0 ; f_{0}(0)=0 ; f_{0}^{\prime}(0)=1 ; f_{0}^{\prime}(\infty)=0 ; \\
& \theta_{0}^{\prime \prime}-\beta^{2} \theta_{0}=0 ; \theta_{0}(0)=1 ; \theta_{0}(\infty)=0 ;
\end{array}\right\} \\
& \left.f_{1}^{\prime \prime \prime}-\alpha^{2} f_{1}^{\prime}+\frac{1}{2}(1-\varphi)^{2.5}\left(1-\varphi+\varphi \frac{\rho_{s}}{\rho_{f}}\right) \times\right) \\
& \times f_{0} f_{0}^{\prime \prime}+\alpha^{2} f_{0}^{\prime}=0 ; \\
& f_{1}(0)=0 ; f_{1}^{\prime}(0)=0 ; f_{1}^{\prime}(\infty)=0 \text {; } \\
& p^{1} \text { : } \\
& \theta_{1}^{\prime \prime}-\beta^{2} \theta_{1}+\frac{\operatorname{Pr}}{2}\left(1-\varphi+\varphi \frac{\left(\rho C_{p}\right)_{s}}{\left(\rho C_{p}\right)_{f}}\right) \times \\
& \times f_{0} \theta_{0}^{\prime}+\beta^{2} \theta_{0}=0 ; \\
& \theta_{1}(0)=0 ; \theta_{1}(\infty)=0 \text {; }
\end{aligned}
$$




$$
\begin{aligned}
& f_{2}^{\prime \prime \prime}-\alpha^{2} f_{2}^{\prime}+\frac{1}{2}(1-\varphi)^{2.5}\left(1-\varphi+\varphi \frac{\rho_{s}}{\rho_{f}}\right) \times \\
& \times\left(f_{0} f_{1}^{\prime \prime}+f_{1} f_{0}^{\prime \prime}\right)+\alpha^{2} f_{1}^{\prime}=0 ; f_{2}(0)=0 ; \\
& f_{2}^{\prime}(0)=0 ; f_{2}^{\prime}(\infty)=0 \text {; } \\
& p^{2}: \\
& \theta_{2}^{\prime \prime}-\beta^{2} \theta_{2}+\frac{\operatorname{Pr}}{2}\left(1-\varphi+\varphi \frac{\left(\rho C_{p}\right)_{s}}{\left(\rho C_{p}\right)_{f}}\right) \times \\
& \times\left(f_{0} \theta_{1}^{\prime}+f_{1} \theta_{0}^{\prime}\right)+\beta^{2} \theta_{1}=0 ; \\
& \theta_{2}(0)=0 ; \theta_{2}(\infty)=0 \text {; }
\end{aligned}
$$

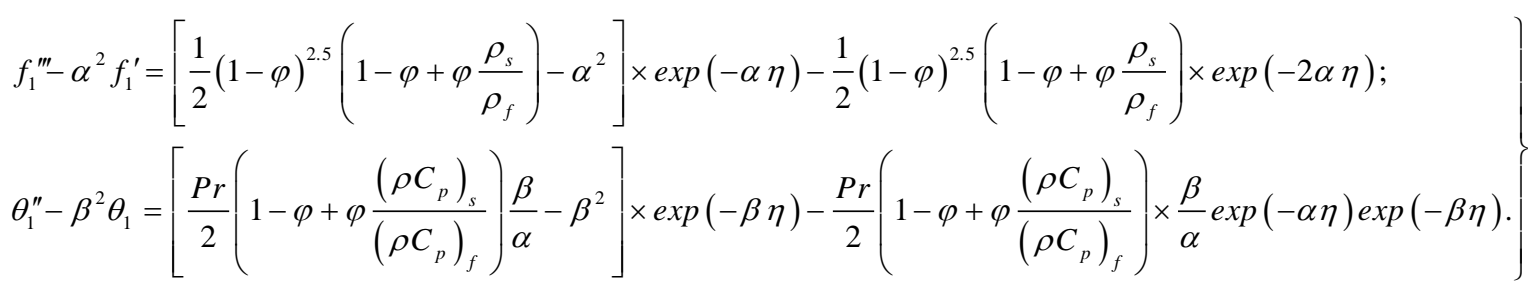

$$
\begin{aligned}
& \left.\begin{array}{l}
f_{0}(\eta)=\frac{1}{\alpha}(1-\exp (-\alpha \eta)) ; \\
\theta_{0}(\eta)=\exp (-\beta \eta)
\end{array}\right\}
\end{aligned}
$$

$f^{\prime}{ }_{1}(\infty)=0$ and $\theta_{1}(0)=0, \theta_{1}(\infty)=0$ in the symbolic software Mathematica, which give:
Eqs. (18) for $f_{1}$ and $\theta_{1}$ were solved in an unbounded domain under the boundary conditions $f_{1}(0)=0, f^{\prime}(0)=0$,

$$
\left.\begin{array}{l}
f_{1}(\eta)=\left(\frac{1}{2 \alpha}-\frac{\Omega}{6 \alpha^{3}}\right)+\left(-\frac{1}{2 \alpha}+\frac{\Omega}{12 \alpha^{3}}\right) \times \exp (-\alpha \eta)+\frac{\Omega}{12 \alpha^{3}} \exp (-2 \alpha \eta) \\
\theta_{1}(\eta)=\left(\frac{1}{2 \beta}-\frac{\Xi}{6 \beta^{3}}\right)+\left(-\frac{1}{2 \beta}+\frac{\Xi}{12 \beta^{3}}\right) \times \exp (-\beta \eta)+\frac{\Xi}{12 \beta^{3}} \exp (-\alpha \eta) \exp (-\beta \eta)
\end{array}\right\}
$$

where:

$$
\alpha=(\Omega / 2)^{0.5} ; \beta=(\Xi / 2)^{0.5} ;
$$

$$
\Xi=\left[1-\varphi+\varphi\left(\left(\rho C_{p}\right)_{s} /\left(\rho C_{p}\right)_{f}\right)\right]
$$

in which $\Omega=(1-\varphi)^{2.5}\left[1-\varphi+\varphi\left(\rho_{s} / \rho_{f}\right)\right]$;

Thus, first-order approximate solutions $f(\eta)=f_{0}(\eta)+f_{1}(\eta)$ and $\theta(\eta)=\theta_{0}(0)+\theta_{1}(\eta)$ are obtained as:

$$
\left.\begin{array}{l}
f(\eta)=\left(\frac{3}{2 \alpha}-\frac{\Omega}{6 \alpha^{3}}\right)+\left(-\frac{3}{2 \alpha}+\frac{\Omega}{12 \alpha^{3}}\right) \times \exp (-\alpha \eta)+\frac{\Omega}{12 \alpha^{3}} \exp (-2 \alpha \eta) \\
\theta(\eta)=\left(\frac{3}{2 \beta}-\frac{\Xi}{6 \beta^{3}}\right)+\left(-\frac{3}{2 \beta}+\frac{\Xi}{12 \beta^{3}}\right) \times \exp (-\beta \eta)+\frac{\Xi}{12 \beta^{3}} \exp (-\alpha \eta) \exp (-\beta \eta)
\end{array}\right\}
$$

According to Eq. (20), the dimensionless plate surface shear stress $f^{\prime \prime}(0)$ and dimensionless plate surface heat transfer rate $\theta^{\prime}(0)$ are as follows:

$$
\left.\begin{array}{l}
f^{\prime \prime}(0)=-\frac{3}{2} \alpha+\frac{5 \Omega}{12 \alpha} \\
\theta^{\prime}(0)=-\frac{3}{2}+\frac{5 \Xi}{12 \beta^{2}}
\end{array}\right\}
$$

\section{Results and discussion}

The HPM semi-analytical solutions of the governing equations, i.e. Eqs. (7) and (8), with boundary conditions of Eq. (9) are obtained using the HPM, by writing a code in symbolic software MATHEMATICA. It should be mentioned that the fluid flow part of the present problem (i.e. Eq. (7)) was investigated in [11] by the authors of the present paper, and the validation investigation in [11] can also be considered as the validation of the present results. Thus, in the present paper, the focus is mainly on the heat transfer part of the problem (i.e. Eq. (8)) and the results are presented only for the heat transfer characteristics. The thermo-physical properties of water and nanoparticles used in the present study are taken from Table 1 .

Table 2 shows the values of the dimensionless temperature gradient at the plate surface $-\theta^{\prime}(0)$ for $\mathrm{Cu}$-water, $\mathrm{Al}_{2} \mathrm{O}_{3}$-water, $\mathrm{TiO}_{2}$-water, $\mathrm{CuO}$-water, $\mathrm{Ag}$-water and $\mathrm{SiO}_{2}$ water nanofluids in different values of nanoparticles volume fraction $\varphi$ using the HPM. It can be seen that $-\theta^{\prime}(0)$ decreases with the increase of $\varphi$. The values of the dimensionless Nusselt group $N u_{x} R e_{x}^{-0.5}$ for various types of nanofluids using HPM are shown in Table 3. It can be observed that the $N u_{x} R e_{x}^{-0.5}$ is an increasing function of $\varphi$.

Fig. 2 indicates the variations of temperature gradient at the plate surface $-\theta^{\prime}(0)$ with the nanoparticles volume fraction $\varphi$ for various types of nanoparticles using HPM. It is well observed that, at a constant $\varphi$, the maximum and minimum values of $-\theta^{\prime}(0)$ belong to the $\mathrm{Cu}$ and $\mathrm{SiO}_{2}$ nanoparticles respectively. It can also be viewed that the augmentation of $\varphi$ has a reducing effect on the $-\theta^{\prime}(0)$ for all types of the nanofluids. 
Table 1

Thermophysical properties of water and nanoparticles [7]

\begin{tabular}{|c|c|c|c|c|c|c|c|}
\hline Property & Fluid Phase (water) & $\mathrm{Cu}$ & $\mathrm{Al}_{2} \mathrm{O}_{3}$ & $\mathrm{TiO}_{2}$ & $\mathrm{CuO}$ & $\mathrm{Ag}$ & $\mathrm{SiO}_{2}$ \\
\hline$\rho\left[\mathrm{kg} / \mathrm{m}^{3}\right]$ & 997.1 & 8933 & 3970 & 4250 & 6500 & 10500 & 2670 \\
\hline$C_{p}[\mathrm{~J} / \mathrm{kg} . \mathrm{K}]$ & 4179 & 385 & 765 & 686.2 & 540 & 235 & 703 \\
\hline$k[\mathrm{~W} / \mathrm{m} . \mathrm{K}]$ & 0.613 & 401 & 40 & 8.9538 & 18 & 429 & 1.3 \\
\hline
\end{tabular}

Values of $-\theta^{\prime}(0)$ for various types of nanofluids using HPM

Table 2

\begin{tabular}{|c|c|c|c|c|c|c|}
\hline$\varphi$ & $\mathrm{Cu}$-water & $\mathrm{Al}_{2} \mathrm{O}_{3}$-water & $\mathrm{TiO}_{2}$-water & $\mathrm{CuO}$-water & Ag-water & $\mathrm{SiO}_{2}$-water \\
\hline 0.0 & 2.33864 & 2.33864 & 2.33864 & 2.33864 & 2.33864 & 2.33864 \\
\hline 0.1 & 2.22370 & 2.20307 & 2.19035 & 2.18214 & 2.17878 & 2.16758 \\
\hline 0.2 & 1.98401 & 1.96132 & 1.92287 & 1.87164 & 1.79767 & 1.63187 \\
\hline
\end{tabular}

Table 3

Values of the dimensionless Nusselt group $N u_{x} R e_{x}^{-0.5}$ for various types of nanofluids using HPM

\begin{tabular}{|c|c|c|c|c|c|c|}
\hline$\varphi$ & $\mathrm{Cu}$-water & $\mathrm{Al}_{2} \mathrm{O}_{3}$-water & $\mathrm{TiO}_{2}$-water & CuO-water & Ag-water & $\mathrm{SiO}_{2}$-water \\
\hline 0.0 & 2.33864 & 2.33864 & 2.33864 & 2.33864 & 2.33864 & 2.33864 \\
\hline 0.1 & 2.96117 & 2.85447 & 2.83924 & 2.81105 & 2.78948 & 2.38785 \\
\hline 0.2 & 3.28550 & 3.15052 & 3.11823 & 3.06054 & 2.90159 & 2.39446 \\
\hline
\end{tabular}

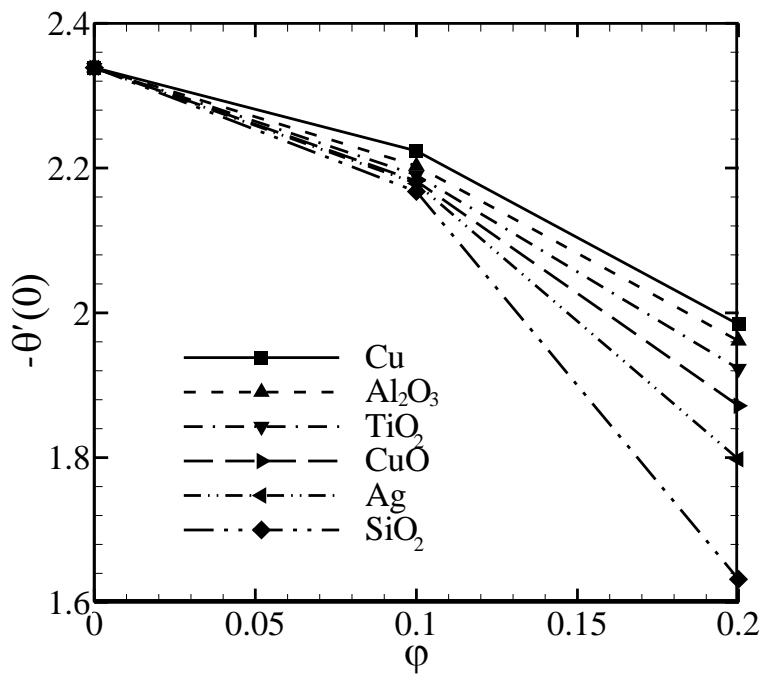

Fig. 2 Variation of $-\theta^{\prime}(0)$ with nanoparticles volume fraction $\varphi$ for various types of nanoparticles using HPM

Fig. 3 shows the dimensionless Nusselt group $N u_{x}$ $\operatorname{Re}_{x}{ }^{-0.5}$ in terms of the nanoparticles volume fraction $\varphi$ for various types of nanofluids. It is worth mentioning that the dimensionless Nusselt group $N u_{x} R e_{x}^{-0.5}$ is an indicator of the heat transfer rate at the plate surface. As it is observed in Fig. 3, the increase of the $\varphi$ causes the increase of $N u_{x} R e_{x}$ 0.5 for all types of nanoparticles. This means that, in order to increase the heat transfer rate on the surface of a plate moving with constant velocity through a stagnant fluid, it is sufficient to add any type of nanoparticles to the fluid. However, according to Fig. 3, the heat transfer rate is also enhanced when higher volume fractions of nanoparticles are added. It is also seen that, at a certain value of $\varphi$, the $\mathrm{Cu}$ nanoparticles provide the highest $N u_{x}$ while the $\mathrm{SiO}_{2}$ nanoparticles provide the lowest values of $N u_{x}$. Thus, compared to other nanoparticles, addition of the $\mathrm{Cu}$ nanoparticles can result in enhanced heat transfer characteristics.

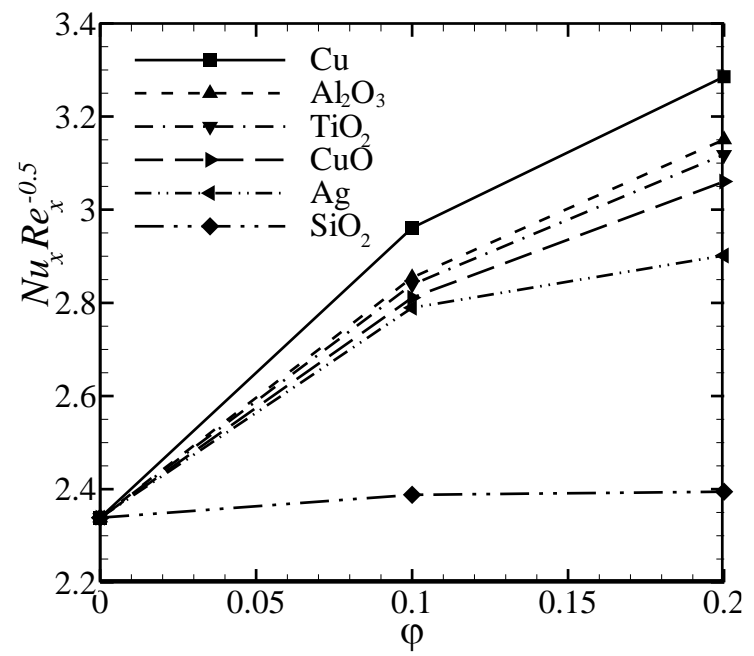

Fig. 3 Variation of the dimensionless Nusselt group $N u_{x} R e_{x}^{-}$ 0.5 with nanoparticles volume fraction $\varphi$ for various types of nanoparticles

In Fig. 4, the variations of the local Nusselt number $N u_{x}$ with the local Reynolds number $R e_{x}$ are demonstrated for some values of the nanoparticles volume fraction $\varphi$ for $\mathrm{Al}_{2} \mathrm{O}_{3}$-water nanofluid. It is observed that, at a certain Reynolds number, $N u_{x}$ enhances with the increase of $\varphi$. It is also seen that the local Nusselt number $N u_{x}$ is an increasing function of the local Reynolds number $R e_{x}$. Fig. 5 illustrates the local Nusselt number $N u_{x}$ in terms of the local Reynolds number $R e_{x}$ for various types of nanoparticles when $\varphi=0.1$. At a certain $R e_{x}, \mathrm{Cu}$ nanoparticles provide the maximum $N u_{x}$, but $\mathrm{SiO}_{2}$ nanoparticles provide the minimum values of $N u_{x}$. Fig. 6 shows the temperature profiles $\theta(\eta)$ for some values of the nanoparticles volume fraction $\varphi$ for $\mathrm{Al}_{2} \mathrm{O}_{3}$-water nanofluid using the HPM. It is noticeable that the nanoparticles volume fraction $\varphi$ has a very low increasing effect on the temperature $\theta(\eta)$. In Fig. 7, the temperature profiles $\theta(\eta)$ are demonstrated for various types of nanoparticles, when $\varphi=0.2$, using the HPM. It can be seen that the temperature 
profiles are very similar for various types of nanoparticles. However, $\mathrm{SiO}_{2}$ nanoparticles result in relatively higher temperature of nanofluid compared to other nanoparticles.

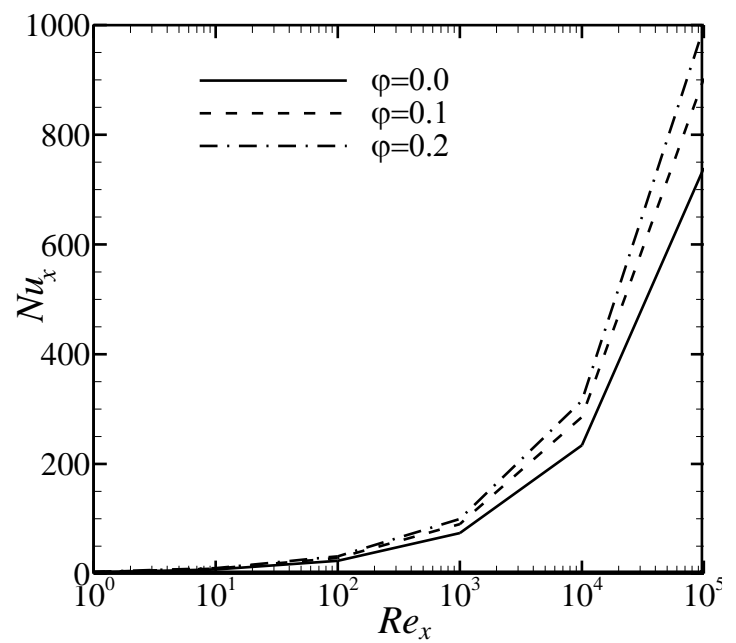

Fig. 4 Variation of the local Nusselt number $N u_{x}$ with Reynolds number $R e_{x}$ for some values of nanoparticles volume fraction $\varphi$ for $\mathrm{Al}_{2} \mathrm{O}_{3}$-water nanofluid

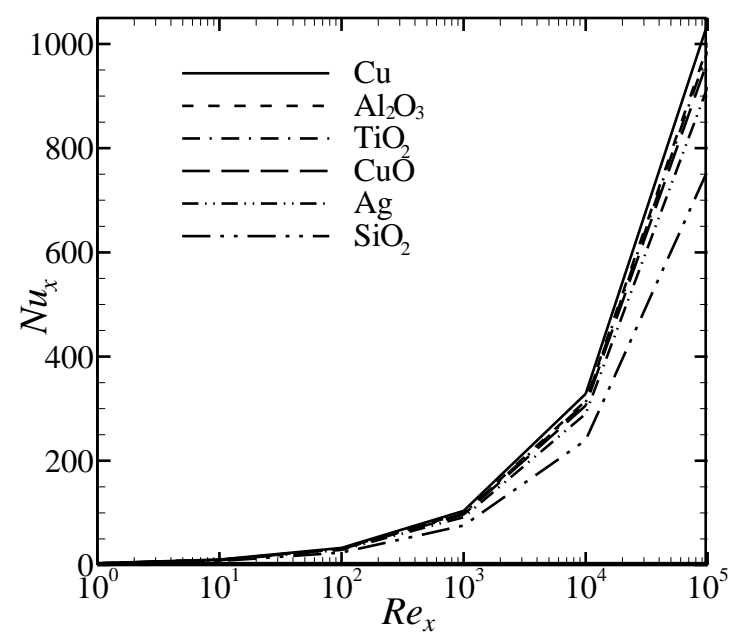

Fig. 5 Variation of the local Nusselt number $N u_{x}$ with Reynolds number $R e_{x}$ for various types of nanoparticles when $\varphi=.1$

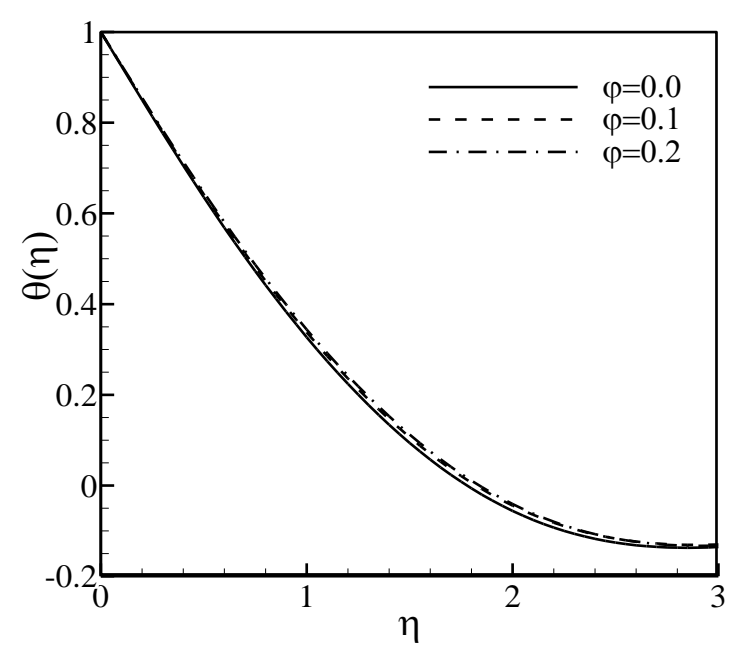

Fig. 6 Temperature profiles $\theta(\eta)$ for some values of nanoparticles volume fraction $\varphi$ for $\mathrm{Al}_{2} \mathrm{O}_{3}$-water nanofluid

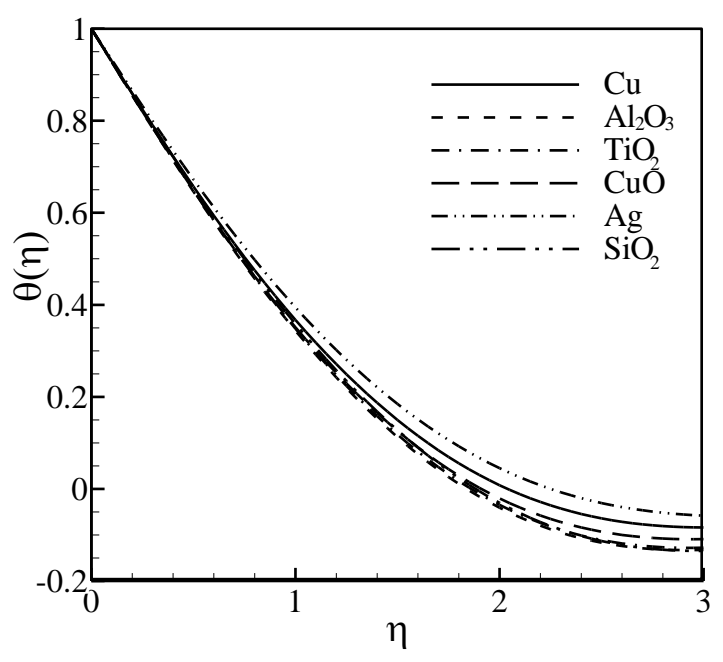

Fig. 7 Temperature profiles $\theta(\eta)$ for various types of nanoparticles when $\varphi=0.2$

\section{Conclusions}

The forced convection heat transfer of various nanofluids over an impermeable moving horizontal flat plate is studied. The governing equations of mass, momentum and energy conservations are transformed by suitable similarity transformations to two nonlinear ODEs which are then solved using the homotopy perturbation method (HPM) for six types of nanoparticles: copper $(\mathrm{Cu})$, alumina $\left(\mathrm{Al}_{2} \mathrm{O}_{3}\right)$, titania $\left(\mathrm{TiO}_{2}\right)$, copper oxide $(\mathrm{CuO})$, silver $(\mathrm{Ag})$ and silicon $\left(\mathrm{SiO}_{2}\right)$ in the water based fluid. The results obtained are as follows:

1) The augmentation of the nanoparticles volume fraction $\varphi$ has a decreasing effect on dimensionless temperature gradient at plate surface $-\theta^{\prime}(0)$ for all types of nanofluids.

2) The increase of $\varphi$ causes increase of $N u_{x} R e_{x}^{-0.5}$ for all types of nanoparticles, which means to increase the heat transfer rate on surface of a plate moving in a fluid, adding any types of nanoparticles to the fluid would be very helpful. Also, the heat transfer rate is more enhanced by adding higher volume fractions of nanoparticles.

3 ) The temperature profiles $\theta(\eta)$ are relatively similar for various types of nanoparticles.

\section{References}

1. Choi, S.U.S.; Zhang, Z.G.; Yu W.; Lockwood, F.E.; Grulke, E.A. 2001. Anomalously thermal conductivity enhancement in nanotube suspensions, Appl. Phys. Lett. 79: 2252-2254.

http://dx.doi.org/10.1063/1.1408272.

2. Maiga, S.E.B.; Palm, S.J.; Nguyen, C.T.; Roy, G.; Galanis, N. 2005. Heat transfer enhancement by using nanofluids in forced convection flow, Int. J. Heat Fluid Flow 26: 530-546.

http://dx.doi.org/10.1016/j.ijheatfluidflow.2005.02.004.

3. Weidman, P.D.; Kubitschek, D.G.; Davis, A.M.J. 2006. The effect of transpiration on self-similar boundary layer flow over moving surfaces, Int. J. Eng. Sci. 44: 730-737. http://dx.doi.org/10.1016/j.ijengsci.2006.04.005.

4. Xu, H.; Liao, S.J. 2008. Dual solutions of boundary layer flow over an upstream moving plate, Commun. 
Non. Sci. Numer. Simul. 13: 350-358. http://dx.doi.org/10.1016/j.cnsns.2006.04.008.

5. Bachok, N.; Ishak, A.; Pop, I. 2010. Boundary-layer flow of nanofluids over a moving surface in a flowing fluid, Int. J. Thermal Sci. 49: 1663-1668. http://dx.doi.org/10.1016/j.ijthermalsci.2010.01.026.

6. Khan, W.A.; Aziz, A. 2011. Natural convection flow of a nanofluid over a vertical plate with uniform surface heat flux, Int. J. of Thermal Sci. 50: 1207-1214. http://dx.doi.org/10.1016/j.ijthermalsci.2011.02.015.

7. Bachok, N.; Ishak, A.; Pop, I. 2012. Flow and heat transfer characteristics on a moving plate in a nanofluid, Int. J. Heat Mass Transfer 55: 642-648. http://dx.doi.org/10.1016/j.ijheatmasstransfer.2011.10.047.

8. Wang, X.Q.; Mujumdar, A.S. 2008. A review on nanofluids - Part I: theoretical and numerical investigations, Brazilian J. Chem. Engng. 25: 613-630. http://dx.doi.org/10.1590/S0104-66322008000400001.

9. Wang, X.Q.; Mujumdar, A.S. 2008. A review on nanofluids - Part II: experiments and applications, Brazilian J. Chem. Eng. 25: 631-648. http://dx.doi.org/10.1590/S0104-66322008000400002.

10. Wang, X.Q.; Mujumdar, A.S. 2007. Heat transfer characteristics of nanofluids: a review, Int. J. Thermal Sci. 46: 1-19. http://dx.doi.org/10.1016/j.ijthermalsci.2006.06.010.

11. Dalir, N.; Nourazar, S.S. 2014. Solution of the boundary layer flow of various nanofluids over a moving semiinfinite plate using HPM, Mechanika 20(1): 57-63. http://dx.doi.org/10.5755/j01.mech.20.1.3406.

12. Ahmad, S.; Pop, I. 2010. Mixed convection boundary layer flow from a vertical flat plate embedded in a porous medium filled with nanofluids, Int. Comm. in Heat and Mass Transfer 37: 987-991. http://dx.doi.org/10.1016/j.icheatmasstransfer.2010.06.004.

13. Bararnia, H.; Ghasemi, E.; Soleimani, S.; Ghotbi,
A.R.; Ganji, D.D. 2012. Solution of the Falkner-Skan wedge flow by HPM-Pade method, Advances in Engineering Software 43: 44-52.

http://dx.doi.org/10.1016/j.advengsoft.2011.08.005.

N. Dalir, S.S. Nourazar

\section{ANALYSIS OF FORCED CONVECTIVE HEAT TRANSFER OF NANOFLUIDS OVER A MOVING PLATE BY THE HOMOTOPY PERTURBATION METHOD}

S u m m a r y

The steady-state two-dimensional laminar forced convection boundary layer heat transfer of various types of nanofluids over an impermeable isothermal moving flat plate is investigated. The governing partial differential equations of mass, momentum and energy conservations are transformed by using suitable similarity transformations to two nonlinear ordinary differential equations (ODEs). The resulting nonlinear ODEs are solved using the semi-analytical treatment of the homotopy perturbation method (HPM) for six types of nanoparticles, namely copper $(\mathrm{Cu})$, alumina $\left(\mathrm{Al}_{2} \mathrm{O}_{3}\right)$, titania $\left(\mathrm{TiO}_{2}\right)$, copper oxide $(\mathrm{CuO})$, silver $(\mathrm{Ag})$ and silica $\left(\mathrm{SiO}_{2}\right)$ in the water based fluid. The effects of solid nanoparticles volume fraction and nanoparticles type on the heat transfer characteristics are investigated and compared with previously published numerical results. The obtained results show that the local Nusselt number increases with the increase of the nanoparticles volume fraction.

Keywords: nanofluids; forced convection; moving plate; HPM solution.

Received August 17, 2015 Accepted November 25, 2015 